\title{
EFFECT MODELLING AND OPTIMIZATION, A NEW METHODOLOGY FOR COMBINED ENERGY AND ENVIRONMENT SYNTHESIS OF INDUSTRIAL PROCESSES
}

\author{
F. Maréchal* and B. Kalitventzeff \\ Laboratoire d'Analyse et de Synthèse des Systèmes Chimiques (LASSC). University of Liège, \\ Sart-Timan B6, B-4000, Liège, Belgium
}

\begin{abstract}
Combining mathematical programming and thermodynamic analysis for solving energy integration of industrial processes appears to be a very powerful tool to target minimum energy cost requirements. Defining the role played by thermodynamic analysis and numerical methods allowed us to define a generic method for calculating the energy integration even of complex industrial sites. The method has been adapted to solve combined energy and environment synthesis of industrial processes. In the approach, different alternative process schemes are included in this superstructure, the optimal structure being extracted using MILP optimization that minimizes the cost of energy, including raw materials, fuels and electricity, rather than just thermal energy. This new modelling approach, that allowed us to target process modifications and improvements has been named EMO (effect modelling and optimization). In the paper, we discuss how the approach has been extended to represent the environmental and energy interactions both in terms of objective functions and constraints. Having developed the mathematical tool, we discuss the role that this tool plays in the engineering method developed to reach combined energy and environmental targets in industrial processes. The generic method has been validated on applications in two major industries: one from the pulp and paper industry and one from the brewing industry. The example of the Kraft pulp process is used to illustrate the application of the approach. (C) European Communities 1997. Published by Elsevier Science Ltd.
\end{abstract}

Keywords-Energy synthesis, process synthesis, environment synthesis, pulp and paper, CAPE.

\section{NOTATION}

ADT

\section{AOx}

BOD

CAPE

CBE

COD

EMO

MER

MCER

MILP

MINLP

MU

\author{
air dry ton of pulp \\ organic chlorine measurement \\ biological oxygen demand \\ computer-aided process engineering \\ cost break-even point \\ chemical oxygen demand \\ effect modelling and optimization \\ minimum energy requirements target \\ minimum cost of energy requirements target \\ mixed integer linear programming \\ mixed integer non-linear programming \\ monetary units
}

\section{INTRODUCTION}

Mathematical programming and thermodynamic analysis play complementary roles in energy synthesis of industrial processes. The method for energy synthesis that we developed previously in JOULE projects implemented the synergy of both approaches into a software named SYNEP. Starting from the formulation of the heat cascade in terms of a mixed integer linear programming (MILP) problem [12], the method then allowed us to calculate the minimum cost of energy requirements target [10]. This new concept corresponds to the selection and the calculation of the optimal flow rates of the utilities that satisfy the minimum energy requirement at minimum cost. Using integer variables allowed us to choose the best among the proposed utility alternatives. This method has been extended to optimize the utility networks, to take into account the restricted

\footnotetext{
*Author to whom correspondence should be addressed.
} 
matches and to calculate the combined heat and mechanical power production [8]. In addition to an automated mathematical formulation, the developments concerned a work method for using it. The mathematical tool allowed us to select among alternatives, while the method gave the user rules of thumbs and tools to propose these alternatives and to evaluate the numerical results obtained. The innovative method has been applied to optimize the energy consumption of industrial chemical sites $[5,6]$.

The key idea of the developments performed by the Laboratoire d'Analyse ct de Synthèse des Systèmes Chimiques (LASSC) from the University of Liège (Belgium) in the Energy and Environment Synthesis in the process industry (ENES) project was to adapt this approach in order to handle the environmental constraints and to study the interrelationships that exist between energy and environmental targets. The methodology and the related computer tools have been developed by LASSC. The method has been validated by the other participants on applications in two major process industries that run not pure chemical plants: one from the pulp and paper industry in collaboration with the Centre Technique du Papier (CTP) in Grenoble (France) and one from the brewing industry in collaboration with WS Atkins Consultants Ltd (UK). The two industrial partners involved in the project provided the data for the problems, commented on the utilization of the method and influenced its development.

\section{A MATHEMATICAL MODELLING TOOL}

\section{Overview of the method}

For combined energy and environment synthesis of industrial processes, we considered the different technologies (or operations) that allow us to increase the energy efficiency and to reduce the environmental impact of a given process. Considering the list of possible techniques, the process was described as a superstructure composed by the operations. Each operation introduced its requirements in terms of consumption or production. The effects considered were of various types: heat, mechanical power, water, raw materials, chemicals, pollutants, etc. When all the effects were considered together, the description of a superstructure by a list of units interconnected in all the feasible manners by streams was not practical. Instead we represented the superstructure via a different effects exchange network. These were represented by exchange flows, balance and feasibility constraints, the interactions between the operations and their effects. In order to compute the best solution, defined as the combination of operations that minimizes the cost of the system, an optimization method was used. The basic mechanism was to extract from the superstructure the operations that had to be used and to compute their level in order to satisfy the effects requirements of the production at minimum cost. This approach has been named EMO (effect modelling and optimization) because the models developed concern the effects and imply both equality and inequality constraints that can only be solved by optimization. Despite the fact that the effect models were submitted to simplifying limitations and assumptions, all had an engineering meaning and the model solved by optimization has been able to show the way for process improvements.

The mathematical optimization model was built with different equations subsets that model the ideal effects exchange network. To illustrate the concept, let us first consider the energy integration to illustrate how the energy integration concepts that concern only the heat effects have been generalized.

\section{Energy requirements}

The hot and cold streams of the process define the heat effect requirements and the heat cascade equations (1) and (2) define the modelling of the ideal heat exchanger network where all exchangers will have a temperature approach greater or equal to a fixed minimum temperature difference (DTmin). This model is used to compute the minimum energy requirements (MER) of the process using, for example, the well known problem table method [9]. When utilities are considered, each possible utility defines an operation. The inlet and outlet temperatures of the hot and colds streams (heat effects) involved in a given utility are considered as a characteristic of the operation and the flow rate has to be computed in order to satisfy the energy requirements at minimum cost. Each 
heat effect from the process or from the utilities introduces its own contributions in the heat cascade. The selection of the operation $w$ was defined by an integer variable $y_{w}$ and the constraints (4). The level of use of the operation $w$ is computed by the multiplication factor $f_{11}$ that multiplies all the effects associated with the operation $w$. The constraints (3) are introduced to impose the overall heat balance of the process. The cost effect appears in the objective function with a proportional term $C_{2 n}$ linked to $f_{\mathrm{w}}$ and a fixed cost $C_{1 \mathrm{w}}$ linked to $y_{\mathrm{w}}$.

$$
\begin{gathered}
\sum_{n=1}^{n_{k}} f_{\mathrm{w}} q_{\mathrm{w} k}+\sum_{i=1}^{n_{\mathrm{h}}} Q_{i k}+R_{k+1}-\sum_{j=1}^{n_{c}} Q_{i k}-R_{k}=0 \quad \forall k=1, \ldots, n_{i} \\
R_{k} \geq 0 \quad \forall k-1, \ldots, n_{i}+1 \\
R_{1}=0, R_{n_{i}+1}=0 \\
\operatorname{fmin}_{w} y_{w} \leq f_{w} \leq \operatorname{fmax}_{w} y_{w} \quad \forall k=1, \ldots, n_{w}, \\
y_{w} \in\{0,1\}
\end{gathered}
$$

with $n_{i}$ the number of temperature intervals; $n_{w}$ the number of alternative operations; $R_{k}$ the heat cascaded from the temperature interval $k$ to the lower one; $Q_{i k}$ the heat load of the stream $i$ in the temperature interval $k ; f_{\mathrm{w}}$ the multiplication factor of the effects linked to the operation $w ; q_{w k}$ the heat load of the thermal effects of the operation $w$ in the temperature interval $k, q_{w k} \geq 0$ for a hot stream; $y_{w}$ the integer variable linked to the use of the operation $w, y_{w}=1$ if it is used, $y_{w}=0$ if not; $f \min _{w}, f \max _{w}$ the minimum and maximum values accepted for $f_{w}$ if $y_{w}=1$.

For more complex utility system, e.g. a steam network, a subset of linear equations (5) and (6) was added to model the links between the different effects. These equations had to be written in such a way that heat balances were verified with respect to the thermal effects defined.

$$
\begin{aligned}
& \sum_{n=1}^{n_{u}} a_{i n} f_{w i}+c_{i n} y_{n}+\sum_{r=1}^{n_{r}} d_{i k}+x_{r}=b_{i} \quad \forall i=1, \ldots, n_{\mathrm{e}} \\
& \sum_{n=1}^{n_{u}} a_{j w} f_{w r}+c_{j w} y_{1 w}+\sum_{r=1}^{n_{r}} d_{j k}+x_{r}=b_{j} \quad \forall j=1, \ldots, n i_{e} \\
& x_{\min } \leqslant x_{r} \leqslant x \max , \quad \forall r=1, \ldots, n_{r},
\end{aligned}
$$

with $n_{\mathrm{e}}$ the number of effect modelling equality constraints; $n i_{\mathrm{e}}$ the number of effect modelling inequality constraints; $n_{r}$ the number of additional linear variables; $x_{r}$ the additional variables used to model the effects of the operation; $a_{i u}, c_{i u}$, respectively, the coefficients of the flow rate and the integer variables of operation $w$ in the constraint $i$ in the effect models $(j$ refers to inequality constraints); $d_{i r}, b_{i}$, respectively, the coefficients of the additional variables and the independent term in the constraint $i$ in the effect models; $x$, the additional variables used to model the effects of the operation; $x \min _{r}, x_{\text {max }}$, respectively, the minimum and maximum bounds of $x_{r}$.

The additional variables $x_{r}$ were used in the model as intermediate variables or to represent the environmental effects. For example, the computation of the overall $\mathrm{CO}_{2}$ emission of the plant was computed by a constraint (5) where $x_{r}$ was the overall $\mathrm{CO}_{2}$ emission of the plant, $n_{r}=1, d_{i r}=1$, $b_{i}=0$ and $a_{i w}$ represented the $\mathrm{CO}_{2}$ production of the operation $w$. The same approach was used to compute the overall COD (chemical oxygen demand), the BOD (biological oxygen demand) and the AOx (measurement of chlorinated organic matters) of the plant.

\section{Combined heat and power integration}

In addition to the thermal effects, the integration of the utilities introduced the effects of mechanical power consumption and/or production. The electricity import or export of the system was computed by adding mechanical power balances (8) and (9), the cost contribution of electricity import $\left(C_{\mathrm{el}}\right)$ and export $\left(C_{\mathrm{elv}}\right)$ being added to the objective function. 
Electricity consumption:

$$
\sum_{n=1}^{n_{\mathrm{w}}} w_{w} f_{\mathrm{n}}+W_{\mathrm{el}}-W_{\mathrm{p}} \geq 0
$$

Electricity production:

$$
\sum_{w=1}^{n_{\mathrm{u}}} w_{\mathrm{u}} f_{w}+W_{\mathrm{el}}-W_{\mathrm{elv}}-W_{\mathrm{p}}=0
$$

with $w_{w}$ the mechanical power produced by the operation $w, w_{w}<0$ for a consumption and $>0$ for a production; $W_{\mathrm{el}}, W_{\mathrm{elv}}$, respectively, the consumption and the production of electricity.

\section{Combined energy and environment: minimizing the water usage}

The concept of effect modelling allowed us to tackle the combined energy and waste minimization problem and to compute the interactions between these two major components. After energy, water usage minimization is an important problem to minimize the environmental impact. The water minimization problem was considered like energy. For each operation, we introduced water requirements in terms of productions and consumptions, the water effects were characterized in terms of quantity and in terms of quality. The water quality has not been introduced as a continuous variable, instead we defined a finite list of different water quality, the quality being defined by the temperature or the pollutant content. The definition of the water quality has mainly been determined from the needs of the different operations involved in the process. Instead of drawing a water cascade, we have used a more flexible approach: the 'water distribution', that defines the water usage in the same way as the heat load distribution [13] does. In the superstructure, each quality level defined a virtual tank where operations input $\left(p_{w i}>0\right)$ or output water $\left(p_{w i}<0\right)$. Furthermore, we allowed for water exchange between the different tanks, the exchange flow being $f_{i j}$. The balances over the different tanks were defined by the constraints (10) and (11), the value of $k_{i j}$ defining the possible exchange flows:

$$
\begin{gathered}
\sum_{n=1}^{n_{u i}} f_{\mathrm{w}} p_{w i}-\sum_{j=1}^{n_{\mathrm{c}}} f_{i j} k_{i j}=0 \quad \forall i=1, \ldots, n_{\mathrm{c}} \\
f_{i j} \geq 0 \quad \forall i=1, \ldots, n_{\mathrm{c}} \text { and } \forall j=1, \ldots, n_{\mathrm{c}},
\end{gathered}
$$

with $n_{\mathrm{c}}$ the overall number of water tanks; $f_{i j}$ the amount of water transferred from tank $i$ to tank $j ; p_{w i}$ the specific water effect of operation $w$ in the effect $i ; p_{w i}>0$ if operation $w$ produces water of quality $i, p_{w i}<0$ if operation $w$ consumes water of quality $i ; f_{w}$ the multiplication factor multiplying the effects of operation $w ; k_{i j}=0$ if the tank $i$ cannot feed the tank $j, k_{i j}=1$ if the tank $i$ can feed the tank $j$.

Obviously, the variables $f_{i j}$ were introduced only when $k_{i j}$ differed from zero. When it was necessary, a mechanical power was associated with the water transfer $f_{i j}$ and when the two tanks had different temperatures, a heat effect was linked to $f_{i j}$. Similarly, when a pollutant was linked to the water transferred, the corresponding effect was linked to $f_{i j}$. In this formulation, we considered the water intake as an operation $w$ with $p_{w i}>0$ and the related mechanical power consumption, as well as the cost effect were added to the corresponding constraints. The treatment plant was considered as one consumption operation $\left(p_{w i}<0\right)$ introducing the corresponding mechanical power and cost effect. The possibility of mixing water with different quality to increase the water recovery was not considered in our study but it can be introduced as an alternative operation $w$ whose coefficients in constraints (10) will be $p_{w i}=-k$ for the higher-quality tank $i$, $p_{u j}=-(1-k)$ for the lower-quality tank $j$ and $p_{u r}=1$ for the resulting quality tank $r$, the coefficient $k$ being a constant that defines the mixing rule in order to reach the medium quality $r$.

The most interesting aspect in this formulation was the fact that the same variable $f_{w}$ defining the level of usage of the alternative operation $w$ in the superstructure was used in the different subsets of the model defining the different effect transfer: the ideal heat transfer network (1)-(4), 
the utility system and the environmental impact (5)-(7), the mechanical power balances (8) and (9), the water network (10) and (11) and the cost effect (12):

$$
\sum_{\mathrm{w}=1}^{n_{\mathrm{u}}}\left(C_{1 \mathrm{li}} y_{\mathrm{w}}+C_{2 \mathrm{w}} f_{\mathrm{wi}}\right)+C_{\mathrm{el}} W_{\mathrm{el}}-C_{\mathrm{elv}} W_{\mathrm{elv}}+\sum_{r=1}^{n_{t}} C_{r} x_{r}-C=0
$$

with $C_{1 w}, C_{2 w}$ fixed and proportional costs linked to the use of the operation $w ; C_{r}$ the cost associated to the additional variables $x_{r} ; C_{\mathrm{el}}, C_{\mathrm{elv}}$, respectively, the cost of importing and selling electricity.

Summing up all these subsets and considering the minimum cost as an objective, we defined the model of the process superstructure. We obtained the EMO (effect modelling and optimization) formulation that is a MILP (mixed integer linear programming) problem defined by:

Minimize $C$

Subject to

$$
\mathrm{R}_{\mathrm{k}} ; \mathrm{y}_{\mathrm{w}} ; \int_{\mathrm{w}} ; \hat{\mathrm{rij}}_{\mathrm{ij}} ; \mathrm{x}_{\mathrm{r}} ; \mathrm{W}_{\mathrm{el}} ; \mathrm{W}_{\mathrm{elv}}
$$

- Cost function (12)

- Heat cascade: (1) to (4)

- Electricity consumption and production: (7) and (8)

- Effect models: (5) and (6)

- Water recycling: (10) and (11)

The interest of this new modeling approach was to generalize the concept of targeting by defining a process superstructure where different technological solutions (e.g. for heat recovery, for water recycling, for pollution abatement) were considered together and where the interactions between the different targets (emissions, energy, cost, mechanical power, water) were taken into account simultaneously.

\section{Effect modelling is a tool for process integration understanding}

The development of the effect models implies an in-depth study of the phenomena involved in each operation. Let us illustrate the EMO approach by the simple case of combustion. Two types of efficiency have to be considered, the first is the local efficiency of combustion, i.e. the heat that can be recovered by the combustion of one unit of fuel; the second is the global efficiency regarding its integration to the system. This means that the fuel flow rate was computed in order to produce the heat required by the process at minimum cost. The global efficiency of the integrated operation is thus different to its local efficiency, since heat is required only above the system pinch point. The development of the effect model of combustion requires the study of the mechanisms involved in combustion. The heat of combustion (Fig. 1) is available from the adiabatic temperature $\left(T_{\text {ad }}\right)$ to the minimum accepted stack temperature $\left(T_{\mathrm{s}}\right)$. The latter is a technological characteristic of the fuel depending, for example, on its sulphur content. Considering the combustion of one unit of fuel with a fixed air excess that has to be chosen as small as possible, we will first consider the standard combustion, fuel and air being taken at the ambient temperature $\left(T_{\mathrm{a}}\right)$. The heat exchange with the fumes can be divided into two sections, the first $(Q R)$ at high temperature, from $T_{\text {ad }}$ to $T_{\mathrm{r}}$ mainly involves radiative heat exchange. As the radiative exchange does not satisfy the assumptions made to calculate the heat cascade, it can be represented by a hot stream at constant temperature $\left(T_{\mathrm{r}}\right.$, fixed arbitrarily to $\left.1100 \mathrm{~K}\right)$. The second section corresponds to a convective counter-current exchange $(Q C)$ from $T_{\mathrm{r}}$ to $T_{\mathrm{s}}$. With respect to the lower heating value (LHV), the heat load $Q R+Q P$ defines the useful heating value (UHV) of the fumes. The latter is the highest heating value of the fuel that can be reached technologically in a classical boiler.

The difference between the LHV and the UHV corresponds to a technological heat loss that defines the local efficiency of the fuel. The two thermal effects are linked to the fuel flow rate $\left(f_{i}\right)$. When considering the integration of the fumes to the process, the pinch point identifies the minimum energy requirements of the process and also the lowest temperature of the heat requirements. Below the pinch point temperature, the heat of the fumes is not more useful for the process. Compared to the UHV, we obtain additional losses (the 'MER heat losses') that correspond to the global efficiency of the fuel. A way to overcome this loss is to preheat air and 


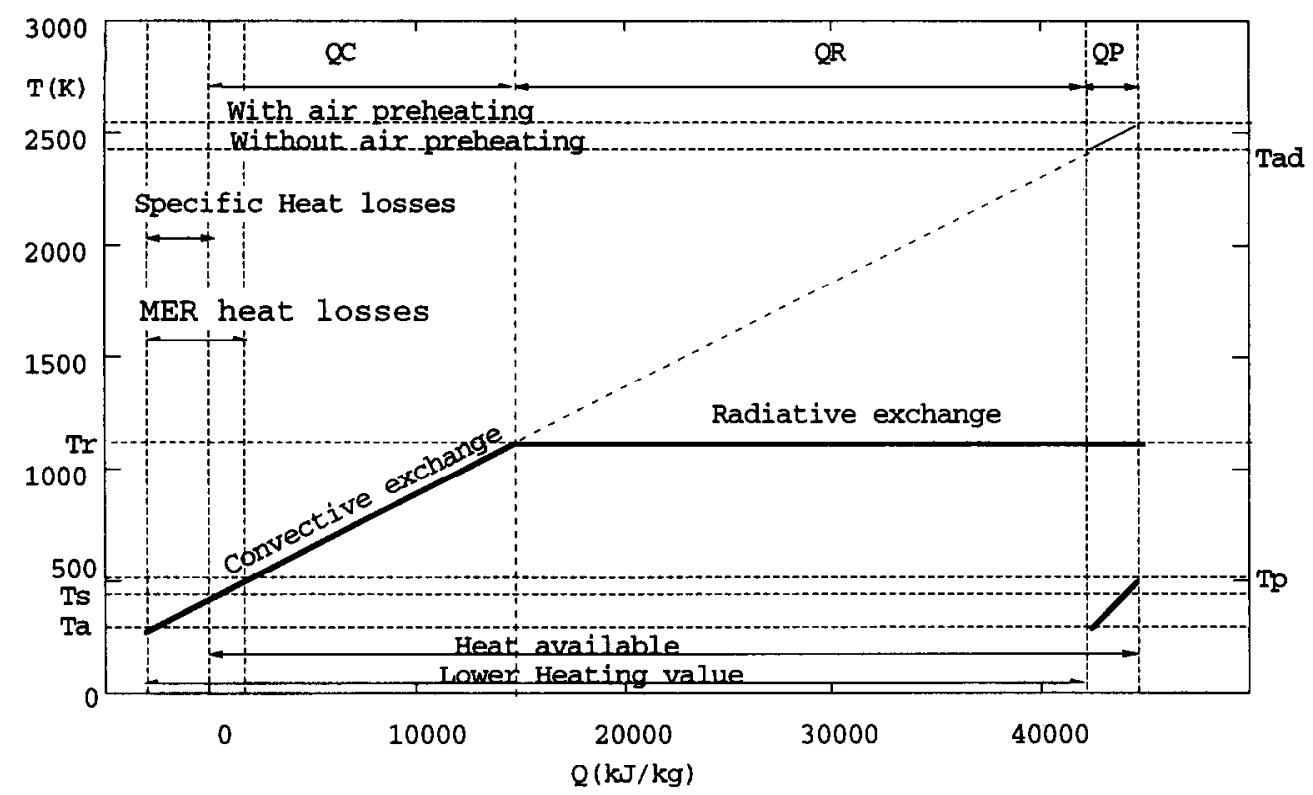

Fig. 1. Combustion and air preheating.

fuel using the excess of energy available below the pinch point. Air preheating defines a cold stream effect that corresponds to the preheating of one unit of air from $T_{\mathrm{a}}$ to the preheating temperature $\left(T_{\mathrm{p}}\right) ; T_{\mathrm{p}}$ is in reality the process pinch point temperature. The flow rate of preheated air $\left(f_{\mathrm{a}}\right)$ was linked to the fuel flow rate by the effect model. The effect of preheating air is an increase of the adiabatic temperature of combustion calculated from its heat load $(Q P)$. By the combustion, the heat load $Q P$ is madc available in the radiative zone, it thus defines a hot stream effect at constant temperature $\left(T_{\mathrm{r}}\right)$ and does not affect the heat available below $T_{\mathrm{r}}$. The thermal effects defining the combustion are summarized in Table 1 (the values correspond to a natural gas, percentages are expressed in terms of LHV).

When the superstructure involves different types of fuels that have to be integrated to the process and the utility systems, calculating the integration cannot be treated easily without optimization. Air preheating was modelled in the EMO approach by adding the following linear constraint (13) that linked the preheated air flow rate $\left(f_{\mathrm{a}}\right)$ to the chosen fuel flow rate $\left(f_{f}\right)$ :

$$
f_{\mathrm{a}} \leq \sum_{f=1}^{n_{f}} f_{\mathrm{f}} \times k_{f},
$$

with $k_{f}$ the stoichiometric coefficient of combustion, it represents the air required for the combustion of one unit of fuel $f$ (in the example $k_{f}=14.62 \mathrm{~kg} / \mathrm{kg}$ of fuel); $n_{f}$ the number of fuels proposed.

This relation indicates that the flow rate of the preheated air must be less than or equal to the air flow rate required by the combustion of the selected fuel. Blowing air in the boiler introduces a mechanical power effect $\left(W_{b}\right)$ that will be related to the fuel flow rate. The simulation of the combustion allowed us to also determine the environmental impact of the combustion in terms of $\mathrm{CO}_{2}, \mathrm{SO}_{x}$ and $\mathrm{NO}_{x}$. These effects were linked to the fuel flow rate and in certain cases to the

Table 1. List of the effects linked to the combustion

\begin{tabular}{llllll}
\hline Effect type & Inlet & Outlet & Effect & Variable \\
\hline Hot stream & $T_{\mathrm{r}}(1100 \mathrm{~K})$ & $T_{\mathrm{r}}(1100 \mathrm{~K})$ & $Q R: 25910 \mathrm{~kJ}(60.2 \%)$ & $f_{f}$ & combustion \\
Hot stream & $T_{\mathrm{r}}(1100 \mathrm{~K})$ & $T_{\mathrm{s}}(373 \mathrm{~K})$ & $Q C: 15494 \mathrm{~kJ}(36 \%)$ & $f_{f}$ & combustion \\
Cold stream & $T_{\mathrm{a}}(298 \mathrm{~K})$ & $T_{\mathrm{p}}(400 \mathrm{~K})$ & $Q P: 103.6 \mathrm{~kJ}(3.5 \%)$ & $f_{\mathrm{a}}$ & air preheating* \\
Hot stream & $T_{\mathrm{r}}(1100 \mathrm{~K})$ & $T_{\mathrm{r}}(1100 \mathrm{~K})$ & $Q P: 103.6 \mathrm{~kJ}(3.5 \%)$ & $f_{\mathrm{a}}$ & air preheating \\
Mechanical & & & $W_{\mathrm{b}}: 75 \mathrm{~kJ}$ & $f_{f}$ & air blowing \\
Environmental & & & $\mathrm{CO}_{2}: 2.36 \mathrm{~kg}$ & $f_{f}$ & $\mathrm{CO}_{2}$ production \\
\hline
\end{tabular}

*Air preheating is expressed in terms of unit of fuel flow rate. 
preheated air flow rate, since the increase of the burning temperature produced an increase of the $\mathrm{NO}_{x}$ production. The use of a given fuel also introduced a cost effect defined with two terms: the fixed and the operating cost. The optimization algorithm chose the fuel to be used, computed its optimal flow rate and the one of the preheated air using the MILP formulation (P1).

The linear programming formulation used in the EMO procedure concerned the optimization of the levels (multiplication factors $f_{w}$ ). The definition of the utility characteristics (i.e. temperatures and compositions) were obtained by simulation. The preheating temperature has thus to be chosen in order to maximize the combustion efficiency in the integrated situation. In the MILP formulation used in the EMO approach, the temperatures could not easily be treated as additional command variables because they define the number of equations. Duran and Grossmann [1] proposed a non-linear approach to solve this problem but it appeared to be difficult to handle, especially in the case of mixed integer programming. Instead of trying to solve complex mixed integer non-linear programming (MINLP) problems, we have integrated the mathematical optimization tool into a three-step work method named AGE (analyse-generate-evaluate) that helps engineers in choosing the appropriate characteristics of the utilities (analyse), extract the optimal solution among the altcrnatives proposed (generate) and help in verifying that the utility characteristics are optimal (evaluate).

The first step used is the grand composite curve analysis to determine the utility characteristics. For example, air preheating has to be performed below the pinch because the process features an excess of heat below the pinch. The air preheating temperature was thus the pinch point temperature. In this case, the air preheating acted as a heat pump, taking heat below the pinch point and making it available above the pinch point. This conclusion has to be adapted when considering the combined heat and power and the integration of the utility network, or when the integration of the fumes created a pinch point above the process pinch point.

\section{AN INTEGRATED CAPE METHOD}

The three-step AGE procedure is a generic tool to solve the problem of combined energy and environment synthesis of industrial processes.

To solve the first step, analyse, the rules for optimal integration of the utility presented by Linnhoff et al. [9] are applied to determine the list of utility alternatives. Additional rules have been developed to choose the appropriate pressure levels of the utility system [10]. A structured approach (Fig. 2) has been developed [7] to analyse the environmental impacts and to propose technological solutions that reduce the global process emissions. The analyse step results in a list of operations to be considered in the superstructure of the industrial system and that will be modelled by the EMO mathematical tool.

The second step, generate, uses the optimization model to calculate the optimal levels of the operations and to select the optimal process configuration. The objective function is the total cost, including fuels, electricity, emissions taxes and investment.

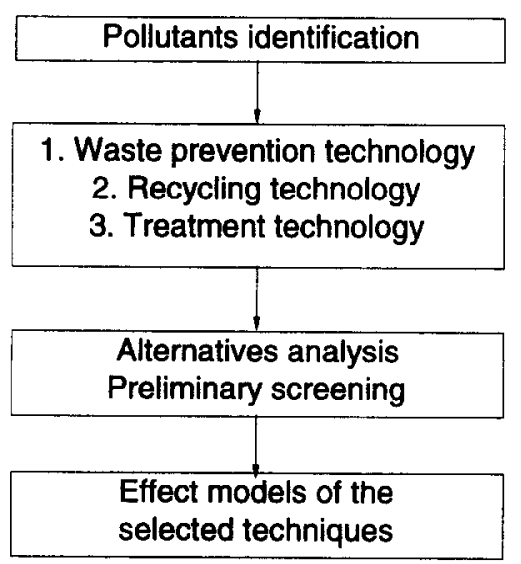

Fig. 2. An overview of the analysis method for the environmental impact. 
The third step, evaluate, exploits the results in two ways. The first concerns the decision aspects of the problem defined by the integer variables, the second concerns the visualization of the integration of the selected alternatives. This allows the identification of possible new operations or process modifications to be considered.

Dealing with alternative operations introduced a new dimension in the problem because the operating cost was not the only factor that had to be considered, investments had to be considered too. Instead of introducing the investment directly in the objective function, we developed the following strategy to evaluate the configurations proposed by the optimization. Each decision was represented by an integer variable. Introducing an integer cut [2] allowed us to generate an ordered list of solutions by successive MILP calculations. Instead of applying the integer cuts on the whole set of integer variables, we applied it on a given set of alternatives that we wanted to be ordered with respect to the objective function. Let us define MILP ${ }^{k}$, the problem solved to generate the $k$ th solution. We defined the next problem (MILP ${ }^{k+1}$ ) using this solution and by adding the integer cut constraint:

Problem MILP ${ }^{k}$

$$
\sum_{j=1}^{n_{k}}\left(\left(2 Y_{j}^{k}-1\right) Y_{j}\right) \leq \sum_{j=1}^{n_{k}} Y_{j}^{k}-1
$$

with $y_{j}^{k}$ the value of the integer variable $y_{j}$ in the solution of problem $k ; n_{y}$ the number of alternatives to be studied.

Successively solving the MILP $^{k}$ problems until the problem became impossible generated an ordered list of optimal solutions that corresponded to different process configurations. For each of the interesting solutions (from an engineer's point of view), we were able to estimate the investments, operating cost, emissions, etc. We then compared the different configurations, defined the rate of return of each one and determined the most profitable investment and its corresponding operating costs. By comparing operating and investment costs, we finally calculated the cost break-even point of one process configuration with respect to another.

To visualize the results of the optimization, we drew the composite curves at the solution. To confirm the thermodynamic characteristics of the thermal effects, we used the integrated composite curves [11] that allowed us to represent the integration of one streams subsection with respect to the others. For the water usage we plotted the water composite curves matching the water productions and consumptions. Note that these were just representations of the optimization results and not a computing method. These representations helped in proposing further process modifications (values of temperatures or pressures, introduction of other operations) whose effect models were added to the process superstructure.

\section{APPLICATION IN THE KRAFT PULP INDUSTRY}

In the ENES study, two major examples have been tackled. In this paper we used the application to the Kraft pulp process to illustrate the method.

A reference Kraft pulp mill process (Fig. 3) has been built by CTP with a simulation model [3]. It included the best known energy efficient technologies. The raw material used was softwood logs. The debarking and chipping allowed us to separate the bark, used for energy production, and the wood, used for pulp production. Debarking was operated with water. The cooking technology considered for the reference mill was a continuous digester, the cooking chemicals (sodium sulfide, soda) were fed with the white liquor. All the data referred to 1 ADT (air dry ton) of pulp. The steam consumption was about 1 ton. The brown pulp was washed counter-currently in the bottom-washing diffuser and filters, with hot water $\left(8 \mathrm{~m}^{3}\right)$ introduced in the last filter. The bleaching consisted of a sequence of oxidation and washing operations. For the reference model, the chemicals used were, successively: $\mathrm{ClO}_{2}, \mathrm{NaOH}, \mathrm{H}_{2} \mathrm{O}_{2}, \mathrm{O}_{2}$. The bleaching temperatures were controlled by steam injections. The steam consumption was about 0.5 ton. For the bleached pulp washing, warm and hot water $\left(16 \mathrm{~m}^{3}\right)$, as well as white water from the paper machine, were used. The acid and the alkaline effluents had to be treated in the effluents treatment plant. The pulp was mechanically dewatered to $52 \%$ dryness in the press section and dried to $90 \%$ in the hot air dryer. 
The steam consumption for drying was 0.8 ton. The weak black liquor contained the oxidized chemicals, the dissolved lignins and water. It was concentrated from 18 to $65 \%$ dryness using a seven effects Uevaporator. The reactants were regenerated in the recovery boiler where the lignins were burnt. The heat of reaction was used to produce steam ( 7 tons of 60 bar steam). Starting from this situation the method has been applied, the main alternative schemes are presented hereafter.

\section{Analysis}

The analysis lead to the identification of different alternative operations, their specific effect will not necessarily be given because, in the superstructure, the interractions between the operations were more important than the stand-alone effects.

Energy efficiency. Due to the barks and the recovery boilers, the process presented an excess of energy that will be exploited by producing and expanding steam. For technological reasons some of the process-process heat exchange was not feasible, the use of a steam network was thus required as an intermediate stream. Analyzing the shape of the process grand composite curve [10] allowed us to identify the optimal pressure value of the headers. By comparison to the reference situation, an additional pressure level corresponding to a condensation turbine has been added. This led to a higher efficiency in the combined production of heat and power. The mechanical power production was increased by $700 \mathrm{MJ} / \mathrm{ADT}$. The efficiency of the recovery section could be increased by introducing an ultra-high-solid concentrator [4] that had been introduced as an alternative. It allowed us to increase the heat produced in the recovery boiler but required evaporation using low-pressure steam. The benefit was expressed in terms of additional mechanical power produced of $221 \mathrm{MJ} / \mathrm{ADT}$. Furthermore, due the reduction of the water content of the fumes, the use of an ultra-high-solid concentrator simultaneously reduced the $\mathrm{SO}_{x}$ emissions of the recovery boiler (not quantified).

Waste-prevention technologies. An oxygen delignification step was introduced as an alternative before the bleaching sequence. It reduced both the chemicals consumed in the bleaching sequence and the effluents produced. This affected heat effects, mechanical power demands, costs and also the effluents produced. Since it did not contain chlorinated compounds, the washing water used in the oxygen delignification could be recycled in the brownstock washing section. The amount of solids recycled in the recovery boiler was thus increased and, since it was mainly composed of lignins that were burnt in the recovery boiler, it influenced the heat effects of the recovery section.

Recycling technologies. Water was reused from washing operations to the others using a counter-current scheme. Condensates from the cooking and the evaporation section were recovered and recycled after stripping, the latter being represented by a cold stream corresponding to the steam demand (proportional to the flow of water stripped). The vapour effluent of the stripping

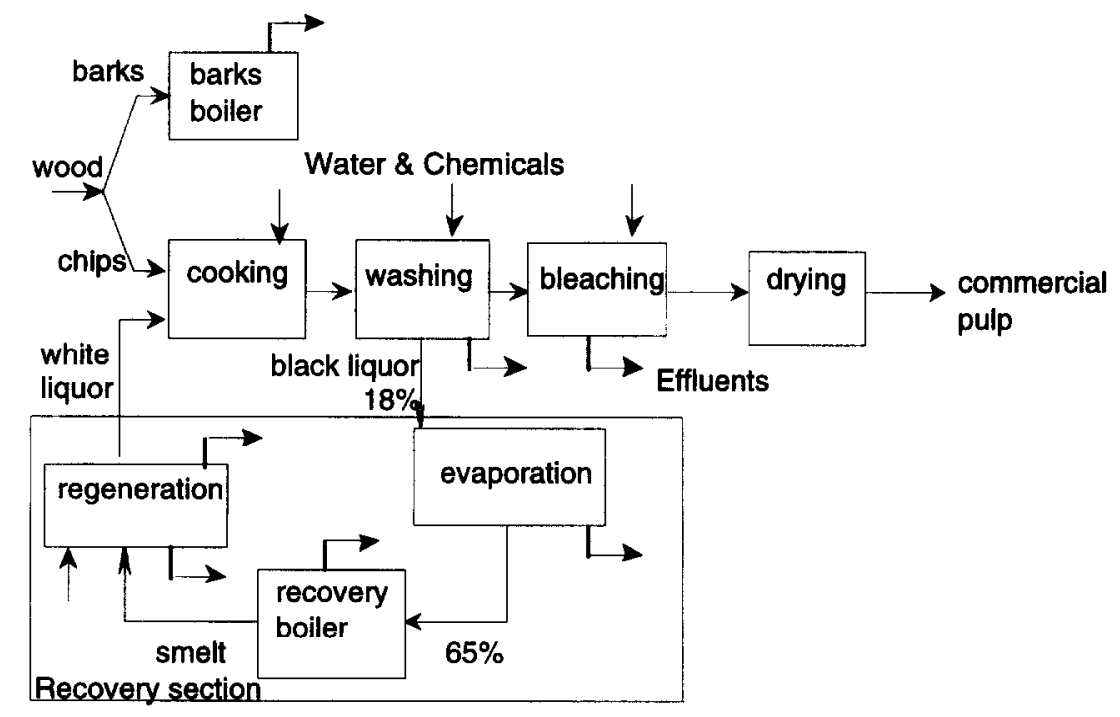

Fig. 3. Schematic description of the Kraft pulp mill process. 
was used as fuel for the lime kiln, where it reduced the natural gas consumption by $\pm 30 \%$. The lignin content of the streams entering the recovery section was linked to an additional heat production effect in the recovery boiler, while the water content defined a heat consumption effect in the evaporation section. When oxygen delignification was used the alkaline effluent could be recycled. In contrast, when oxygen delignification was not selected, recycling the alkaline effluent of the bleaching section was only possible when using ultrafiltration [15]. This introduced a new alternative linked to mechanical power and effluent production effects in the model. Acid effluent could not be recycled.

Waste treatment. In the actual situation, the water treatment plant collected the cooling water of the process. Introducing a cooling tower system as an alternative allowed us to increase the water treatment plant efficiency, to reduce the water effluent by $30 \%$ and to proportionally reduce its mechanical power consumption. Conversely, it introduced a mechanical power demand that was linked to the cooling system load.

\section{Generate}

All the alternatives have been included in a global process superstructure. Details of the model developed can be found in refs [7] and [14]. The utility network superstructure was considered in the same model; that allowed us to extract the optimal process and utility system configuration that minimized the operating costs.

\section{Evaluate}

Using the integer cuts, we generated an ordered list of solutions presented according to increasing operating costs; this allowed us to evaluate the results obtained by comparing targets. For reasons of confidentiality, values are expressed in terms of arbitrary monetary units.

In Fig. 4, the different optimal configurations are presented in terms of operating costs, investments, total costs and payback time by comparison to the reference situation. The COD (chemical oxygen demand) emissions are also presented.

From the total cost point of view, we can observe that several solutions are very close. This means that the final choice will strongly depend on the cost parameters used for the evaluation. The optimal configuration will thus be determined according to the chosen target. The interest of the EMO approach was that all the solutions were simultaneously computed during the same run. These represented the interactions between the different choices, i.e. the cvolution of the level of use as a function of the chosen technologies. The comparison of the different solutions might be
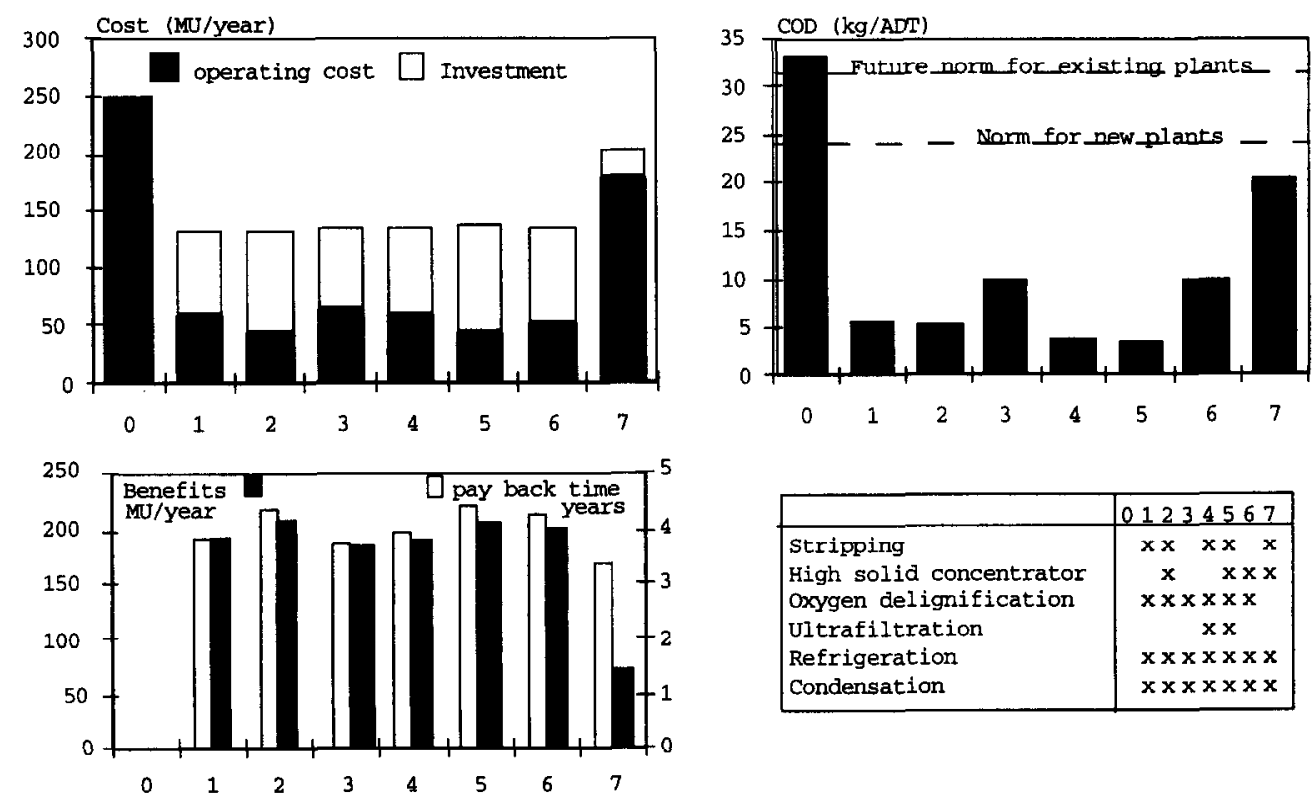

Fig. 4. Criteria for evaluating and comparing the configurations (MU = monetary units). 
used to compute the cost break-even (CBE) point of the technologies. For example, we compared solutions 1 and 2 to compute the CBE point of the high-solid concentrator and its sensitivity to the other cost parameters. The integration of the high-solid concentrator corresponded to an increase of the net mechanical power produced of $208 \mathrm{MJ} / \mathrm{ADT}(9.5 \%)$, an increase of water recycling of $2.52 \%$ that was made possible by the use of stripping, the latter allowing a reduction of the natural gas consumption in the lime kiln of $2 \%$. In the example, the cost of electricity played a very important role.

From an operating cost point of view, the best solution (No. 2) corresponded to a benefit of $82.8 \%$ with respect to the reference situation. It led to a higher investment, mainly due to the use of the ultra-high-solid concentrator. As the process produced heat, the benefit of the process was obtained by the combined production of mechanical power that can be sold to the net or to the related paper machine. The process improvements corresponding to the recycling of water also increased the energy production in the recovery boiler that led to an increase of the mechanical power production ( $+978 \mathrm{MJ} / \mathrm{ADT}$ ). The best solution corresponded to an increase of $70 \%$ of the electricity net production and to a reduction of $30 \%$ of the natural gas production.

From an environmental point of view, the best solution is solution No. 5. With respect to the reference situation, it resulted in a reduction of $88 \%$ of the COD and of $71 \%$ of the AOx in the water effluent that was reduced by $67 \%$. The total cost $(+3 \%)$ was increased mainly by reason of the increase of the related investment $(+23 \%)$.

\section{CONCLUSIONS}

The method developed in the ENES project was the first step of a new approach based on the combined use of numerical optimization involving mixed integer programming and process thermodynamic analysis. The mathematical formulation approach that has been named EMO (effect modelling and optimization) allowed us to simultaneously take into account various effects, like heat exchange, mechanical power, emissions, raw materials consumptions, etc. The model was made of different superstructures that concern the process itself and the utility system and that include the different alternative technologies. Using cost as an objective function allowed us to target the minimum cost of energy and environmental requirements. One of the characteristics of the approach was that utilities were considered simultaneously with the process to define the target. That means that the list of streams to be considered in the heat exchanger network design included the utility streams that were determined on a minimum cost basis. The use of the mathematical model were integrated into a generic work method based on the three AGE steps: analyse, generate, evaluate; this allowed us to provide the engineer with a practical method that provoked its creativity and allowed the evaluation and comparison of different process configurations based on combined energy and environmental targets.

The approach was applied to the Kraft pulp process as an illustration. The application of the method showed an energy saving of $70 \%$ in terms of the operating cost, while the emissions were reduced of $62 \%$ in terms of water effluent, $83 \%$ in terms of COD and $68 \%$ in terms of AOx. The order of magnitude of the payback time was 5 years. The results showed that several solutions with similar total costs might be obtained. The choices have to be made using other criteria, like environmental impact, cost parameter sensitivity. Comparing the different process configurations also allowed us to compute the cost break-even point of the different technologies.

Acknowledgements - The authors wish to express their thanks to the European Commission (DGXII) for financing their RT and D activities in the field of rational use of energy and environment synthesis in the process industry.

\section{REFERENCES}

1. M. A. Duran and I. E. Grossmann. Simultaneous optimisation and heat integration of chemical processes. $A I C h E J$. 32, 1 (1986).

2. M. A. Duran and I. E. Grossman. A mixed-integer nonlinear programming algorithm for process systems synthesis. AIChE J. 32, 4, 592-606 (1986).

3. F. Guillet, G. Lombarbo, E. Muratore and D. Klein, Détermination des Potentialités d'Economies d'Energie dans l'Industrie Française des Pâtes Kraft à l'aide d'un Modèle Exergétique-document CTP No. 1580, Grenoble (1992). 
4. R. E. Harrison, P. J. Cheng, B. A. Crowell and E. A. Ketcham, Ultra-high solids evaporation of black liquor. Tappi $J$., February (1988).

5. B. Kalitventzeff and F. Maréchal, Process retrofit: incentives for using pinch technology concepts and adequate computer tools. 4th World Congress of Chemical Engineering, Strategies 2000, Karlsruhe, 16-21 June 1991.

6. B. Kalitventzeff, Make use of the utility network to obtain flexible heat exchanger network satisfying the minimum energy requirement. Energy Efficiency in Process Technology, Edited by P. A. Pilavachi, pp. 905-914. Elsevier Applied Science, London (1993).

7. B. Kalitventzeff, F. Maréchal, F. Guillet, M. Pichon and A. Loose, ENES, energy and environment synthesis of industrial processes, final report. CEC JOULE R and D "Rational Use of Energy" (JOUE2-CT92-0166) (1995).

8. B. Kalitventzeff, F. Maréchal, J.-M. Cransfeld and M. Tomiello, Energy synthesis in industrial processes, project SYNEP plus, final report CEC JOULE R and D "Rational Use of Energy" (JOUE-CT91-88) (1994).

9. B. Linnhoff et al., A User Guide on Process Integration for the Efficient Use of Energy. The Institution of Chemical Engineers, Rugby (1982).

10. F. Maréchal, Méthode d'analyse et de synthèse energétiques des procédés industriels, Ph.D Thesis, LASSC, University of Liège, Belgium (1995).

11. F. Maréchal and B. Kalitventzeff. Targeting the minimum cost of energy requirements: a new graphical technique for evaluating the integration of utility systems. Computers and Chemical Engng 6, 225-230 (1996).

12. F. Maréchal and B. Kalitventzeff, Heat and power integration: a MILP approach for optimal integration of utility systems. Proc. 22nd Symp. of the Working Party on use of Computers in Chemical Engineering, COPE'91, Barcelona, 14-16 October 1991, Edited by L. Puigjaner and A. Espurĩa, pp. 185-190 (1991).

13. F. Maréchal and B. Kalitventzeff. SYNEP1: a methodology for energy integration and optimal heat exchanger network synthesis. Computers and Chemical Engng 13, 4/5, 603-610 (1989).

14. F. Maréchal and B. Kalitventzeff, Process synthesis under energy and environmental constraints, application to paper and pulp process. Proc. Large Chemical Plants 9, Antwerpen, 4-6 October 1995, Edited by Koninklijke Vlaamse Ingenieursvereniging, pp. 351-362 (1995).

15. E. Muratore, M. Pichon, P. Monzie and J. Rodeaud. Bleach plant effluent treatment by ultrafiltration-mill site experience. Pulp and Paper Canada 84, 6 (1983). 